\title{
Rituximab for refractory subcutaneous Sweet's syndrome in chronic lymphocytic leukemia: A case report
}

\author{
SEYED MEHDI HASHEMI ${ }^{1,2}$, SEYED AMIRHOSSEIN FAZELI ${ }^{3}$, \\ ABDOLBASET VAHEDI $^{4}$ and REZA GOLABCHIFARD ${ }^{3}$
}

\begin{abstract}
${ }^{1}$ Division of Hematology and Medical Oncology, Department of Internal Medicine, School of Medicine, Zahedan University of Medical Sciences; ${ }^{2}$ Division of Hematology and Medical Oncology, Department of Internal Medicine, Ali-Ebne-Abitaleb Hospital; ${ }^{3}$ Department of Internal Medicine, School of Medicine;

${ }^{4}$ Students' Scientific Research Center, Zahedan University of Medical Sciences, Zahedan, Iran
\end{abstract}

Received June 30, 2015; Accepted November 27, 2015

DOI: $10.3892 / \mathrm{mco} .2015 .715$

\begin{abstract}
Sweet's syndrome is a neutrophilic dermatosis characterised by sudden onset of fever, neutrophilia, erythematous skin rashes and neutrophilic infiltration of the dermis. Subcutaneous Sweet's syndrome, or Sweet's panniculitis, is an uncommon variant of the classic syndrome, with hypodermal neutrophilic infiltration. The association of Sweet's syndrome with various malignancies has been reported. The most common underlying hematological malignancies are of myeloid origin; however, there have been several reports of the classic Sweet's syndrome in patients with a lymphoproliferative disorder, although the association of subcutaneous Sweet's syndrome with lymphoproliferative disorders has not been well-documented thus far. Herein, we present the case of a 48-year-old man with a 2-year history of chronic lymphocytic leukemia who developed fever and skin rashes, without any evidence of a relapse. The clinical and pathological investigation resulted in the diagnosis of subcutaneous Sweet's syndrome. The patient exhibited no significant response to conventional therapeutic measures; however, following two subsequent doses of rituximab, his general condition and skin rash improved. The follow-up skin biopsy demonstrated dermal neutrophilic infiltrations in conjunction with prior mixed lobular and septal panniculitis, suggesting evolution of subcutaneous Sweet's syndrome to its classic form. To the best of our knowledge, this is one of the first reports of rituximab as a novel biological treatment for Sweet's syndrome. However, further randomized trials are required to evaluate the efficacy and safety of such biological therapies for Sweet's syndrome.
\end{abstract}

Correspondence to: Dr Seyed Amirhossein Fazeli, Department of Internal Medicine, School of Medicine, Zahedan University of Medical Sciences, 1st Kilometer, Persian Gulf Highway, Zahedan 9816743111, Iran

E-mail: sa.fazeli@gmail.com

Key words: subcutaneous Sweet's syndrome, panniculitis, refractory, chronic lymphocytic leukemia, rituximab

\section{Introduction}

Neutrophilic dermatoses include a group of inflammatory conditions of the skin, characterised by polymorphonuclear infiltration. Sweet's syndrome is a neutrophilic dermatosis with dermal involvement that may be associated with hematological malignancies $(1,2)$. Sweet's syndrome is characterised by sudden onset of fever, neutrophilia, erythematous skin lesions and neutrophilic infiltration of the dermis on skin biopsy $(3,4)$. Malignancy-associated Sweet's syndrome is often associated with the discovery or recurrence of the underlying malignancy and it is more common in myelogenous leukemia compared with lymphoproliferative disorders $(5,6)$.

Subcutaneous Sweet's syndrome (Sweet's panniculitis) is a variant with certain different clinical and pathological characteristics, which distinguish it from the classic syndrome. In particular, the subcutaneous fat rather than the dermis is the main site of neutrophilic infiltration. The number of cases with this variant reported to date is limited (7). However, to the best of our knowledge, no association between lymphoproliferative disorders and subcutaneous Sweet's syndrome has been reported to date.

Rituximab is a monoclonal antibody (anti-CD20) that has been shown to be effective in certain dermatological disorders, particularly when standard systemic therapies are ineffective or contraindicated (8).

In this report, we present a patient with chronic lymphocytic leukemia (CLL) with refractory subcutaneous Sweet's syndrome, and report the patient's clinical response to treatment with rituximab. To the best of our knowledge, this is one of the first reports on rituximab as a novel biological therapy for Sweet's syndrome.

\section{Case report}

A 48-year-old man with a 2-year history of CLL developed fever and skin lesions in December, 2013. Following the diagnosis of CLL (Rai stage IV), the patient received several chemotherapeutic regimens, including cyclophosphamide, vincristine and prednisolone (CVP; 4 cycles), chlorambucil-prednisolone (1 cycle) and rituximab, fludarabine and 
cyclophosphamide (RFC; 4 cycles). Furthermore, during his last course of chemotherapy, he received multiple doses of granulocyte colony-stimulating factor (G-CSF). Complete remission had been achieved 3 months prior to admission and the patient was under surveillance.

Four days prior to the onset of fever and skin rash, thrombocytopenia without any other symptoms was detected on the last surveillance visit. Peripheral blood smear and bone marrow examination revealed no evidence of relapse and dexamethasone pulse therapy ( $40 \mathrm{mg} / \mathrm{day} /$ for 4 days) was administered with the diagnosis of autoimmune thrombocytopenia. Following the fourth dose of dexamethasone, the patient developed fever, chills, malaise, dyspnea, headache and myalgia. After 2 days, painful skin rashes appeared at the back of the legs, anterior surface of the left thigh, mons pubis, lower abdomen and anterior chest, followed by additional similar lesions within the next 2 days. The rash was not associated with pruritus. Celecoxib, indomethacin and prednisolone were administered and the pain in some lesions was diminished; however, enlargement of the skin lesions and edema persisted, despite treatment. The patient reported red urine colour and edema of the lower extremities within the next few days. Given the progression of the symptoms, colchicine was added to the treatment.

On the 10th day after the onset of symptoms, the patient was admitted to the emergency department of our center. The patient had no history of any other underlying disease. A history of war injuries and exposure to a blast wave were reported.

On admission, the patient's vital signs were as follows: blood pressure, $80 / 60 \mathrm{mmHg}$; pulse rate, 100 beats $/ \mathrm{min}$; respiratory rate, 14 breaths $/ \mathrm{min}$; and temperature, $36.7^{\circ} \mathrm{C}$. A dermatological examination revealed 5 mobile, well-defined, erythematous, subcutaneous, painful periareolar masses on the chest, varying in size from 2 to $8 \mathrm{~cm}$. There were also firm, indurated, well-defined, erythematous, painful lesions in the right lower abdomen and mons pubis $(5 \times 5 \mathrm{~cm})$. Similar lesions, sized $4 \times 4 \mathrm{~cm}$ were identified in the left lower abdomen. Indurated, well-defined, erythematous, painful plaques were observed in the left middle thigh and posterolateral part of the left lower limb, with a size varying from 1 to $4 \mathrm{~cm}$. There was also pitting edema of the lower extremities (Fig. 1).

Other physical findings included diffuse wheezing and coarse crackles in the lungs, and mild abdominal distention. No lymphadenopathy, organomegaly or arthritis were present.

The laboratory examination results were as follows: white blood cell count, $7.6 \times 10^{9} / 1$, with $96.6 \%$ neutrophils and $2.4 \%$ lymphocytes (Table I); hemoglobin concentration, $9.3 \mathrm{~g} / \mathrm{dl}$ (mean corpuscular volume, $89 \mathrm{fl} / \mathrm{cell}$ ); platelet count, 38x10 $/ 1$; erythrocyte sedimentation rate, $34 \mathrm{~mm} / \mathrm{h}$ (normal, $0-15 \mathrm{~mm} / \mathrm{h}$ ); and C-reactive protein level, $113 \mathrm{mg} / \mathrm{l}$ (normal, $<6 \mathrm{mg} / \mathrm{l}$ ). In the biochemical tests, the blood urea nitrogen was $65 \mathrm{mg} / \mathrm{dl}$; the creatinine level was $2.1 \mathrm{mg} / \mathrm{dl}$; the lactate dehydrogenase level was $257 \mathrm{IU} / \mathrm{l}$; and the albumin level was $2.5 \mathrm{~g} / \mathrm{dl}$.

The bone marrow biopsy revealed a reactive and hypercellular marrow. The myeloid:erythroid ratio was 4-5:1 and the lymphocytes were $<10 \%$, with an increased proportion of promyelocytes to myelocytes (Fig. 2). There was no evidence of relapse.

The skin biopsy revealed an unremarkable epidermis and a thick dermis, with multilayered collagenous bundles. The hypodermis was infiltrated by mature polymorphonuclear

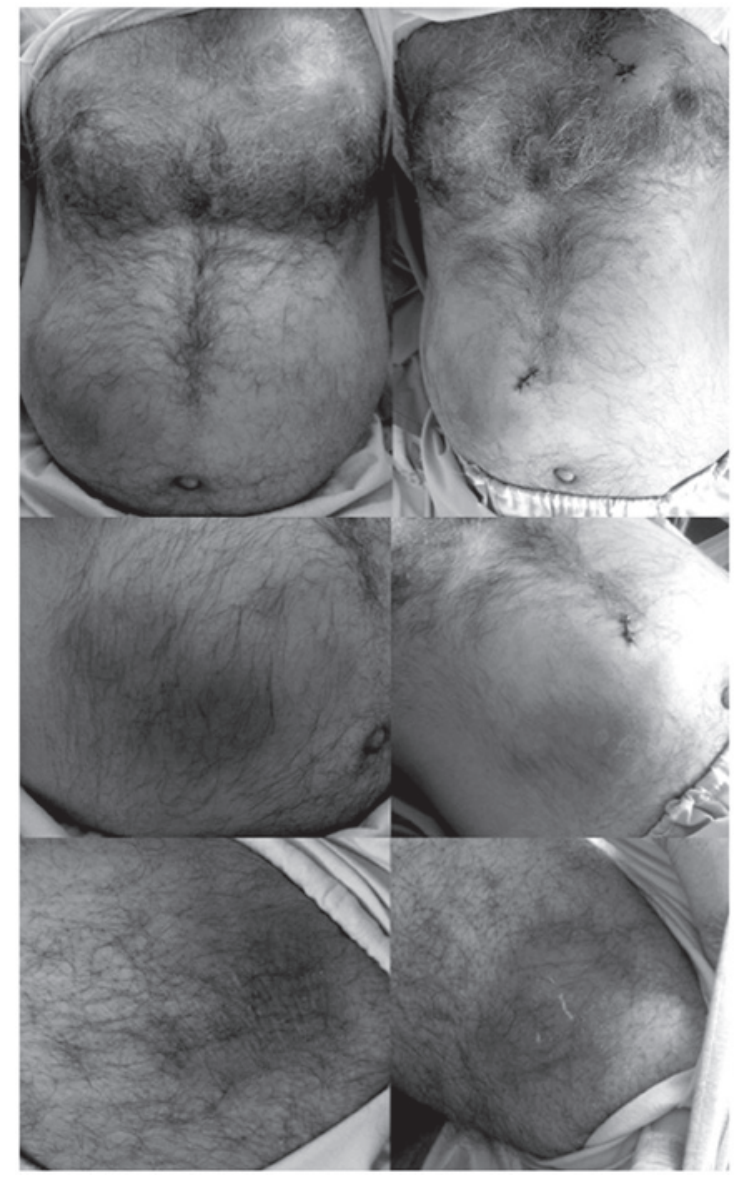

Figure 1. The patient's inflammatory skin rashes in different body regions, prior to (left) and following (right) treatment with rituximab. Top panels, chest and abdomen; middle panels, right lower abdomen; lower panels, left thigh.

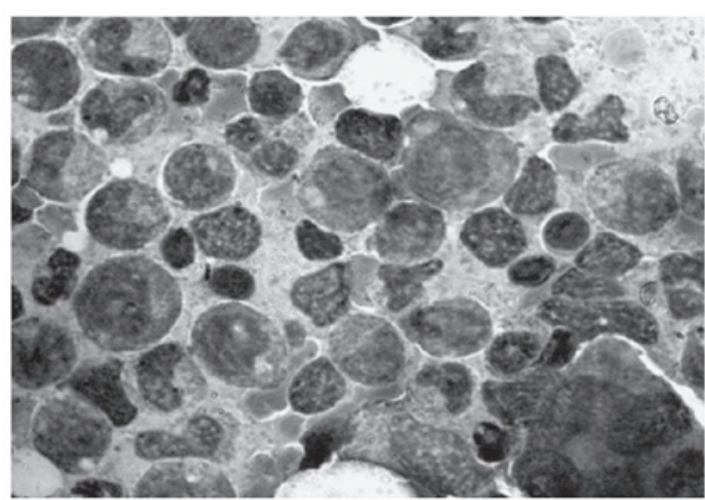

Figure 2. Bone marrow aspirate showing a reactive and hypercellular marrow, without evidence of chronic lymphocytic leukemia relapse.

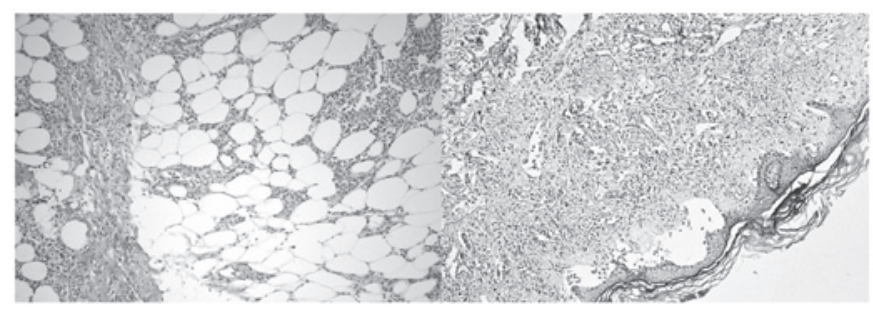

Figure 3. Primary (left) and follow-up (right) skin biopsies demonstrating initial Sweet's panniculitis and subsequent dermal neutrophilic infiltration, respectively. 
Table I. Changes in the patient's blood cells counts following onset of symptoms.

\begin{tabular}{lcccccccccc}
\hline & \multicolumn{10}{c}{ Days } \\
\cline { 2 - 10 } Variables & 10 th & 11 th & 12 th & 13th & 14 th & 17th & 18th & 21 st & 22nd & 25th \\
\hline WBC $(/ \mu l)$ & 7,600 & 11,200 & 7,000 & 5,700 & 8,100 & 5,500 & 2,600 & 1,900 & 2,200 & 3,500 \\
Seg $(\%)$ & 96.6 & 97.5 & 96 & 88.4 & 93.4 & 95.1 & 83.2 & 67.6 & 71.0 & 70.7 \\
Lymph $(\%)$ & 2.4 & 0.6 & 2.7 & 4.7 & 3.3 & 3.8 & 7.0 & 14.5 & 14.7 & 15.2 \\
Hb (g/dl) & 9.3 & 10.7 & 10.8 & 11.9 & 10.3 & 8.5 & 8.4 & 8.7 & 8.1 & 8.6 \\
MCV (fl) & 89.0 & 88.6 & 83.9 & 83.9 & 87.2 & 81.6 & 81.1 & 81.3 & 83.2 & 85.1 \\
Plt (/ml) & 38000 & 44000 & 56000 & 59000 & 64000 & 36000 & 64000 & 69000 & 78000 & 80000 \\
\hline
\end{tabular}

WBC, white blood cells; Seg, segmented neutrophils; Lymph, lymphocytes; Hb, hemoglobin; MCV, mean corpuscular volume; Plt, pleatelets .

Table II. Summary of the clinical course and therapeutic measures.

\begin{tabular}{|c|c|c|}
\hline Time point & Clinical event(s) & Therapeutic measure(s) \\
\hline Last surveillance visit & $\begin{array}{l}\text { Diagnosis of autoimmune } \\
\text { thrombocytopenia }\end{array}$ & Dexamethasone pulse therapy \\
\hline $\begin{array}{l}\text { 1st day } \\
\text { (onset of symptoms) }\end{array}$ & $\begin{array}{l}\text { Onset of skin rash } \\
\text { (last dose of dexamethasone) }\end{array}$ & $\begin{array}{l}\text { Celecoxib (100 mg t.d.s.); } \\
\text { indomethacin ( } 75 \mathrm{mg} \text { b.i.d.); } \\
\text { prednisolone ( } 5 \mathrm{mg} \text { daily) }\end{array}$ \\
\hline 9th day & Progression of symptoms & $\begin{array}{l}\text { Addition of colchicine }(0.5 \mathrm{mg} \mathrm{q} 2 \mathrm{~h} \text { up to } \\
8 \text { times) }\end{array}$ \\
\hline $\begin{array}{l}\text { 10th day } \\
\text { (day of admission) }\end{array}$ & & $\begin{array}{l}\text { Discontinuation of prednisolone, indomethacin } \\
\text { and colchicine } \\
\text { Initiation of: } \\
\text { Rituximab (1st dose) } 375 \mathrm{mg} / \mathrm{m}^{2} \text { body surface; } \\
\text { hydrocortisone ( } 200 \mathrm{mg} \text { i.v. stat before } \\
\text { rituximab, then } 100 \mathrm{mg} \text { i.v. t.d.s.); } \\
\text { celecoxib ( } 100 \mathrm{mg} \text { p.o. b.i.d.); } \\
\text { ceftriaxone ( } 2 \mathrm{gr} \text { i.v. stat, then } 1 \text { gr i.v. b.i.d.); } \\
\text { cimetidine ( } 400 \mathrm{mg} \text { i.v. stat before rituximab) }\end{array}$ \\
\hline 13th day & No improvement in symptoms & $\begin{array}{l}\text { Reinstitution of: } \\
\text { Indomethacin ( } 75 \mathrm{mg} \text { p.o. b.i.d.); } \\
\text { colchicine ( } 1 \mathrm{mg} \text { p.o. daily) }\end{array}$ \\
\hline 15 th day & Progression of limb and scrotal edema & $\begin{array}{l}\text { Triamterene H (1 tab p.o. daily); } \\
\text { hydrocortisone ( } 100 \mathrm{mg} \text { i.v. b.i.d.) }\end{array}$ \\
\hline \multirow[t]{3}{*}{ 18th day } & Continuous limb and scrotal edema & $\begin{array}{l}\text { Rituximab ( } 2 \text { nd dose); } \\
\text { furosemide ( } 40 \mathrm{mg} \text { i.v. daily) }\end{array}$ \\
\hline & Continued wheezing & $\begin{array}{l}\text { Discontinuation of indomethacin; } \\
\text { colchicine (1 mg p.o. b.i.d.); } \\
\text { hydrocortisone ( } 100 \mathrm{mg} \text { i.v.t.d.s.) }\end{array}$ \\
\hline & Positive urine culture and antibiogram result & $\begin{array}{l}\text { Discontinuation of ceftriaxone; } \\
\text { imipenem ( } 250 \mathrm{mg} \text { t.d.s.) }\end{array}$ \\
\hline 19th day & $\begin{array}{l}\text { Decreased upper limb edema and patient's } \\
\text { weight; no dyspnea }\end{array}$ & \\
\hline 21 st day & Disappearance of fever & \\
\hline 22nd day & $\begin{array}{l}\text { Reduced pain and tenderness in skin lesions } \\
\text { Improved superficial features of the rash }\end{array}$ & \\
\hline 28th day & Discharge with good general condition & \\
\hline
\end{tabular}


cells into and between the subcutaneous adipocytes. Few foci of lymphocyte and polymorphonuclear lymphocyte (PMN) infiltration into the vessels wall were observed. The pathological examination was compatible with mixed septal and lobular neutrophilic panniculitis (Fig. 3). Urine culture was positive for Pseudomonas, which was treated with suitable antibiotics. The blood culture was negative.

Following hospital admission, prednisolone, indomethacin and colchicine were discontinued. Hydrocortisone and ceftriaxone were introduced and celecoxib was continued. The first dose of rituximab ( $375 \mathrm{mg} / \mathrm{m}^{2}$ body surface) was administered. On the 18th day, a second rituximab dose was administered and, given the patient's wheezing, indomethacin was discontinued (Table II).

From the 19th day onwards, the patient's condition started to improve. Upper limb edema and the patient's weight decreased and there was no complaint of dyspnea. The fever had disappeared since the 21st day. On the 22nd day, the patient observed a reduction in the pain and tenderness of the skin lesions and the examination revealed minor alterations in the superficial characteristics of the rash (Fig. 1).

Our patient was discharged in a good general condition, 28 days aftert the onset of fever and skin rash. A follow-up skin biopsy revealed a very thin epidermis and an edematous fibrotic dermis, with a diffuse dermal infiltrate of mature PMNs, as well as moderate red blood cell extravasation. There was previous evidence of septal and lobular panniculitis (Fig. 3). Approximately 2 months later, the patient succumbed to septic shock.

\section{Discussion}

We herein report the case of a CLL patient with refractory neutrophilic dermatosis not responding to conventional therapeutic regimens. However, after receiving two doses of rituximab, the patient's symptoms and general condition improved.

On the primary skin biopsy, unlike the classic Sweet's syndrome, which is characterised by dermal infiltration by PMNs (7), the neutrophilic infiltration was seen in hypodermis. Accordingly, the terms 'subcutaneous Sweet's syndrome' (7) or 'Sweet's panniculitis' (9) may be used. The pathological examination revealed mixed lobular and septal panniculitis. The most common reported pattern for subcutaneous Sweet's syndrome is lobular panniculitis. However, there are some reports of a mixed pattern in the literature (7).

The follow-up skin biopsy revealed a neutrophilic infiltration of the dermis in conjunction with prior mixed lobular and septal neutrophilic panniculitis. These findings indicate that subcutaneous Sweet's syndrome may evolve to a classic Sweet's syndrome, despite systemic treatment.

We described a lymphoproliferative disorder as the underlying hematological malignancy in our patient; however, myeloid leukemia appears to be more commonly associated with this syndrome in the literature $(5,6)$. Sweet's syndrome is usually accompanied with evidence suggesting the onset, relapse or recurrence of the underlying malignancy in similar reports $(3,5,10-12)$. However, in our patient, the leukemia was in remission. To the best of our knowledge, the association of subcutaneous Sweet's syndrome and lymphoproliferative disorders has not been priorly reported.
The head, neck, upper and lower limbs, are the predominant regions affected in Sweet's syndrome (6). In our patient, the lesions were located on the anterior wall of abdomen and chest, as well as in the lower extremities, with an ascending pattern of development. This pattern of involvement is unusual in classic Sweet's syndrome; however, the majority of the cases of subcutaneous Sweet's syndrome have been associated with lower extremity involvement (7).

Given the positive urine culture, infectious panniculitis was considered as a differential diagnosis. However, the disease course and relief of the lesions following rituximab treatment, but not with antibiotic therapy, excluded this possibility.

Our patient received G-CSF as part of his chemotherapeutic regimen for up to 4 months prior to the development of the skin lesions. A review of the literature indicated a similar association between treatment with G-CSF and development of Sweet's syndrome (13). The patient's rash had appeared following a high-dose pulse of dexamethasone. The literature search yielded no report on neutrophilic dermatosis following dexamethasone administration.

Various treatments have been proposed for Sweet's syndrome to date and, although it is a self-limiting disease, timely recognition and appropriate treatment may reduce its morbidity (6). The first-line systemic drugs are corticosteroids, potassium iodide and colchicine, with second-line drugs including indomethacin, clofazimine, cyclosporine and dapsone (14). Other successful methods, such as biological treatments with tumor necrosis factor antagonists, have been reported (14). There are several reports on the beneficial effects of the interleukin-1 receptor antagonist anakinra on neutrophilic dermatoses (15-17). In addition, limited reports have investigated other biological agents for the treatment of Sweet's syndrome, such as adalimumab (18), immunoglobulin $(19,20)$ and infliximab $(18,21)$.

Rituximab affects the progression of the cell cycle and is used as an adjunctive to chemotherapy in the treatment of neoplasms. The volume of evidence on the benefits of rituximab in the treatment of autoimmune diseases is currently growing and it is suggested that rituximab may also be helpful in certain dermatological conditions (22).

To the best of our knowledge, this is one of the first reports the role of rituximab for the treatment of Sweet's syndrome has been documented. In our patient, an improvement in the general condition and skin lesions, as well as a reduction in the neutrophil count following administration of rituximab, suggest that this biological agent may be a novel treatment for refractory Sweet's syndrome. However, future randomized trials are required to study its efficacy and side effects.

\section{References}

1. Assari R, Ziaee V, Parvaneh N and Moradinejad MH: Periodic fever and neutrophilic dermatosis: Is it Sweet's syndrome? Case Reports Immunol 2014: 320920, 2014.

2. Prat L, Bouaziz JD, Wallach D, Vignon-Pennamen MD and Bagot M: Neutrophilic dermatoses as systemic diseases. Clin Dermatol 32: 376-388, 2014.

3. Thompson MA, Dyson SW and Faderl S: Sweet's syndrome in chronic lymphocytic leukemia associated with neutropenic fever and granulocyte colony-stimulation factor. Am J Hematol 81: 703-705, 2006.

4. Sweet RD: An acute febrile neutrophilic dermatosis. Br J Dermatol 76: 349-356, 1964. 
5. Cohen PR: Sweet's syndrome - a comprehensive review of an acute febrile neutrophilic dermatosis. Orphanet J Rare Dis 2: 34, 2007.

6. Dabade TS and Davis MD: Diagnosis and treatment of the neutrophilic dermatoses (pyoderma gangrenosum, Sweet's syndrome). Dermatol Ther 24: 273-284, 2011.

7. Guhl G and Garcia-Diez A: Subcutaneous Sweet syndrome Dermatol Clin 26: 541-551, 2008.

8. Bhandari PR and Pai VV: Novel applications of rituximab in dermatological disorders. Indian Dermatol Online J 5: 250-259, 2014.

9. Cullity J, Maguire B and Gebauer K: Sweet's panniculitis. Australas J Dermatol 32: 61-64, 1991

10. Usul Afşar C, Paydaş S, Günaldi M, Bozkurt Duman B, Erçolak V, Zorludemir S and Açikalin A: Sweet syndrome in a patient with chronic lymphocytic leukemia/small lymphocytic lymphoma: Curious lymphocyte/neutrophil fluctuations. Turk J Haematol 30: 413-415, 2013.

11. Cholongitas E, Pipili C, Dasenaki M and Kaklamanis L: Piperacillin/tazobactam-induced Sweet syndrome in a patient with chronic lymphocytic leukemia and autoimmune cholangitis. Am J Dermatopathol 30: 203-204, 2008.

12. Tageja N, Giorgadze T and Zonder J: Dermatological complications following initiation of lenalidomide in a patient with chronic lymphocytic leukaemia. Intern Med J 41: 286-288, 2011

13. Reuss-Borst MA, Müller CA and Waller HD: The possible role of G-CSF in the pathogenesis of Sweet's syndrome. Leuk Lymphoma 15: 261-264, 1994.

14. Cohen PR: Neutrophilic dermatoses: A review of current treatment options. Am J Clin Dermatol 10: 301-312, 2009.
15. Lipsker D, Perrigouard C, Foubert A and Cribier B: Anakinra for difficult-to-treat neutrophilic panniculitis: IL-1 blockade as a promising treatment option for neutrophil-mediated inflammatory skin disease. Dermatology 220: 264-267, 2010.

16. Kluger N, Gil-Bistes D, Guillot B and Bessis D: Efficacy of anti-interleukin-1 receptor antagonist anakinra (Kineret ${ }^{\circledR}$ ) in a case of refractory Sweet's syndrome. Dermatology 222: 123-127, 2011.

17. Delluc A, Limal N, Puéchal X, Francès C, Piette JC and Cacoub P: Efficacy of anakinra, an IL1 receptor antagonist, in refractory Sweet syndrome. Anne Rheum Dis 67: 278-279, 2008.

18. Karamlou K and Gorn AH: Refractory Sweet syndrome with autoimmune organizing pneumonia treated with monoclonal antibodies to tumor necrosis factor. J Clin Rheumatol 10: $331-335,2004$

19. Gill HH, Leung AY, Trendell-Smith NJ, Yeung CK and Liang R Sweet syndrome due to myelodysplastic syndrome: Possible therapeutic role of intravenous immunoglobulin in addition to standard treatment. Adv Hematol 2010: 328316, 2010.

20. Haliasos E, Soder B, Rubenstein DS, Henderson W and Morrell DS: Pediatric Sweet syndrome and immunodeficiency successfully treated with intravenous immunoglobulin. Pediatr Dermatol 22: 530-535, 2005.

21. Lobo AM, Stacy R, Cestari D, Stone JH, Jakobiec FA and Sobrin L: Optic nerve involvement with panuveitis in Sweet syndrome. Ocul Immunol Inflamm 19: 167-170, 2011.

22. Schafranski MD, Merlini AB, Hungaro AC, Luciano JJ and Schumacher MS: Rituximab: Update on pharmacology and clinical applications. 